\title{
Removal of Lead from Aqueous Solutions by Xerogel Film Supported on Activated Carbon and Silica
}

\author{
M.M.Selim", N.A.Youssef *, K. F. Mahmoud" and F. Abdel \\ Samee* \\ Dept. Phys. Chemistry, National Research Center and *Faculty \\ of Girls, Ain Shams University, Cairo, Egypt.
}

\begin{abstract}
CARBON xerogel (X), a kind of novel carbon material with lowdensity and continuous nano-porous structure that can be controlled and tailored on nanometer scale, has been prepared through the sol-gel polycondensation of resorcinol $(\mathrm{R})$ with formaldehyde $(\mathrm{F})$ followed by drying at ambient pressure and carbonization in inert atmosphere. Batch adsorption experiments were performed to find out the effective lead removal at different metal ion concentrations. Removal of lead from aqueous solutions by adsorption onto xerogel film supported on activated carbon and silica has been performed. The removal of $\mathrm{Pb}$ ions from aqueous solutions was studied by batch method. The effects of initial metal concentrations, initial $\mathrm{pH}$, contact time and the quantity of adsorbents were investigated. It was found that carbon xerogel supported on activated carbon exhibited the best adsorption potential for removal of lead ions from solutions.
\end{abstract}

Keywords : Lead removal,Xerogel, Activated carbon, Silica and Coating.

The presence of heavy metals in the aquatic environment has been of great concern to scientists and engineers because of their increased discharge, toxic nature, and other adverse effects on receiving waters. Unlike most organic pollutants, heavy metals are generally refractory and cannot be degraded or readily detoxified biologically. Hence the safe and effective disposal of wastewater containing heavy metals is always a challenge to industrialists and environmentalists, since cost-effective treatment alternative is not available. In recent years, $\mathrm{Pb}$ has been introduced into natural water from a variety of sources such as storage batteries, lead smelting, tetraethyl lead manufacturing, mining, plating, ammunition, and the ceramic glass industries ${ }^{(1)}$.

The permissible limit of lead in drinking water is $0.05 \mathrm{mg}^{-1(2)}$. The presence of excess lead in drinking water causes diseases such as anemia, encephalopathy, and hepatitis. Lead ions have an affinity for ligands containing thiol and phosphatic groups and they inhibit the biosynthesis of hemi, causing damage both to the kidney and liver; this behavior of lead is similar to that of calcium.

\#Author for correspondences E-mail mmaselim@yahoo.com 
However, $\mathrm{Pb}$ can remain immobilized for years, and hence it is difficult to detect the metabolic disorders it causes. The problems connected with heavy metal pollution are curtailed by processes such as precipitation, electrode deposition, ultra-filtration, cementation, selected solvent extraction, activated carbon adsorption, ion exchange, and biological processes ${ }^{(3)}$. Adsorption is an attractive process, in view of its efficiency and the ease with which it can apply to the treatment of waste water containing heavy metals.

The use of adsorbents such as modified groundnut husk ${ }^{(4)}$, olive stones ${ }^{(5)}$, lignite material, bagasse and fly ash, peanut hull carbon, $\mathrm{Fe}(\mathrm{III}) / \mathrm{Cr}(\mathrm{III})$ sludge, bentonite, water biogas residual slurry, crude coniferous bark, modified sawdust, and sugar beet pulp ${ }^{(6)}$ for the removal of $\mathrm{Pb}(\mathrm{II})$ from aqueous solution has been reported.

A carbon gel can be synthesized by the sol-gel polycondensation of resorcinol $(\mathrm{R})$ with formaldehyde $(\mathrm{F})$ using sodium carbonate as a basic catalyst, followed by drying and pyrolysis in an inert atmosphere ${ }^{(7-11)}$. The resulting nanostructure is very sensitive to the various synthesis and processing conditions. The RF organic gels undergo two main steps during synthesis. The first one is the preparation of the sol mixture, and aging. The second one is the drying of the wet gel. During the preparation of the sol, the most important parameters that affect the properties of the gel are catalyst concentration, the initial gel $\mathrm{pH}$ and concentrations of the solids in the gel.

In this paper, systematic laboratory investigations of the removal of $\mathrm{Pb}$ (II) from aqueous solutions by adsorption onto xerogel film supported on activated carbon (AC) and silica (Si), were performed.

\section{Materials and Methods}

\section{Adsorbate}

A stock solution of $\mathrm{Pb}$ (II) (1000 ppm) was prepared by dissolving a required quantity $\mathrm{Pb}\left(\mathrm{NO}_{3}\right)_{2}$ for $\mathrm{Pb}$ (II). Dilute metal ion solutions were prepared as required by further dilution with distilled water $\mathrm{Pb}\left(\mathrm{NO}_{3}\right)_{2}$ in deionized water.

\section{Adsorbent}

Xerogel film supported on activated carbon and silica

RF gels were prepared according to the method of Pekala ${ }^{(12)} .1 .5990 \mathrm{~g}$ resorcinol (R), and $0.0308 \mathrm{~g}$ sodium carbonate as catalyst (both from Merck), were dissolved in $48 \mathrm{ml}$ distilled water. After homogenizing with $2.2 \mathrm{ml} \mathrm{37 \%}$ aqueous formaldehyde $(\mathrm{F})$, the $\mathrm{pH}$ of the solution was set to 6.0 by adding dilute $\mathrm{HNO}_{3}$. The solution was stirred for $30 \mathrm{~min}$ and poured into activated carbon (ml/gm) which was then cured at $85^{\circ} \mathrm{C}$ for 7 days. The carbon xerogel was formed by calcination in an inert atmosphere at $800{ }^{\circ} \mathrm{C}$ during $2 \mathrm{hr}$.

Reagents

All the chemicals were of analytical-reagent grade .

Egypt. J. Chem. 53, No.1 (2010) 
Apparatus

Perkin-Elmer 2380 atomic absorption spectrometer was used for determination of lead. The flame type was air acetylene. The $\mathrm{pH}$ values of the solutions were adjusted by adding $\mathrm{HCl}$ or $\mathrm{HNO}_{3}$ and controlled with a digital pH-meter (model 231).

\section{Adsorption experiments}

Batch adsorption experiments were carried out at room temperature by shaking a series of bottles containing the desired quantity of adsorbent in a predetermined concentration of heavy metal solution. Samples were withdrawn at different time intervals. Supernatant was separated by filtration and analyzed for remaining heavy metal content. Experiments were carried out at initial $\mathrm{pH}$ values ranging from 2.8 to 5.8. The initial $\mathrm{pH}$ of the solution was adjusted to the desired value either by hydrochloride acid or sodium hydroxide solution. The percent removal of heavy metal from solution was calculated by the following equation:

$$
\% \text { Adsorption }=\frac{\mathrm{Co}-\mathrm{Ce}}{\mathrm{Co}} \times 100
$$

where $C_{o}$ is initial concentration of heavy metal, $C_{e}$ is final concentration of heavy metal.

\section{Results and Discussion}

\section{Characteristics of adsorbing material}

Scanning electron microscopic photographs of activated carbon, Figure 1 shows the surface texture and porosity of the sample. The availability of pores and internal surface is requisite for an effective adsorbent.

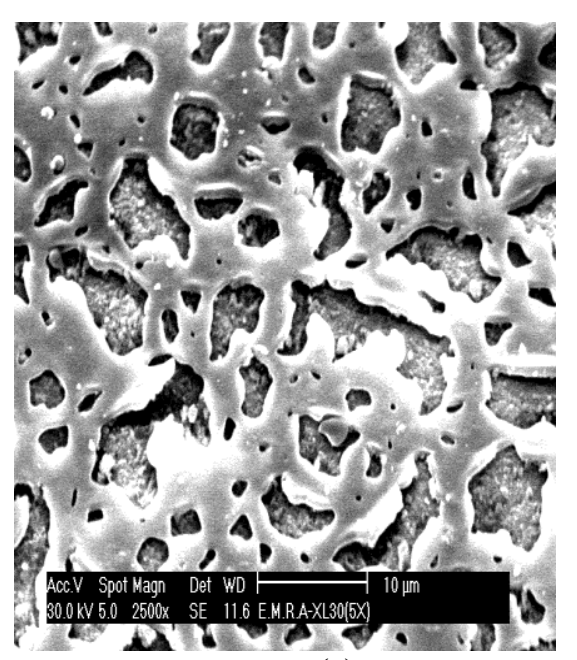

(a)

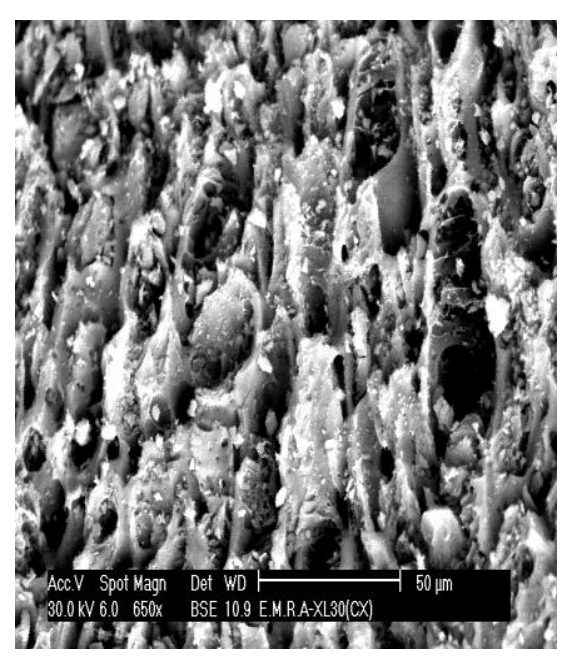

(b)

Fig. 1. Scanning electron micrographs of the two adsorbents, (a) SiX, (b) CX. 
Effect of initial concentration of heavy metal

The effect of initial concentration on the percentage removal of lead by xerogel film supported on activated carbon and silica, is shown in Fig. 2. It can be seen from this figure that the percentage removal decreases with the increase in initial concentration.

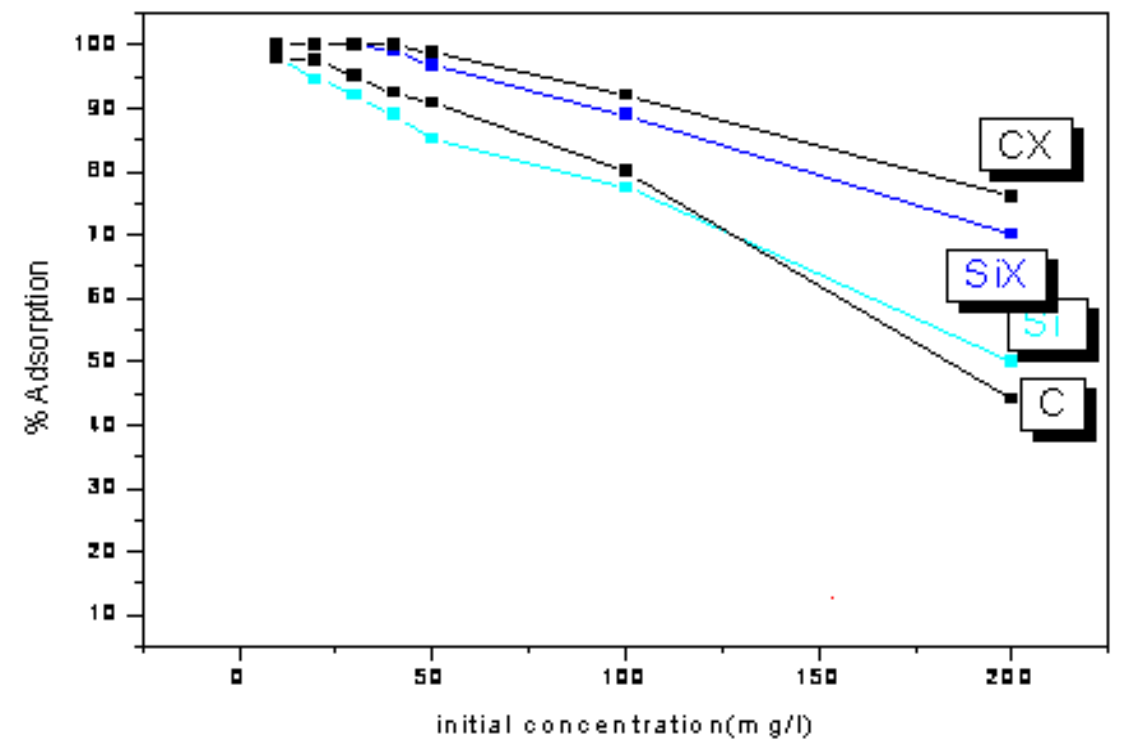

Fig. 2. Effect of initial concentration on adsorption of $\mathrm{Pb}$ (II) (contact time $30 \mathrm{~min}$, $0.2 \mathrm{~g} / 20 \mathrm{ml}$ solution, initial $\mathrm{pH}$ of solution 5.8, temp., $298 \mathrm{~K})$.

The effect of initial concentration on the percentage removal of $\mathrm{Pb}$ (II) ions by $\mathrm{CX}, \mathrm{SiX}, \mathrm{AC}$ and $\mathrm{Si}$ is shown in Fig. 2. From this figure it is seen that the adsorption of $\mathrm{Pb}$ (II) decreased gradually from $100 \%$ to $76 \%$ for $\mathrm{CX}$, from $100 \%$ to $70 \%$ for $\mathrm{SiX}$, from $98 \%$ to $44 \%$ for $\mathrm{AC}$ and from $97 \%$ to $50 \%$ for $\mathrm{Si}$ by increasing the $\mathrm{Pb}$ (II) concentration from $10 \mathrm{mg} / \mathrm{l}$ to $200 \mathrm{mg} / \mathrm{l}$, respectively. Sufficient adsorption sites are available at lower initial concentration, but at higher concentration metal ions are greater than adsorption sites. Thus it can be said that removal of lead is highly concentration dependent.

\section{Effect of adsorbent quantity}

The effect of adsorbent quantity on removal of $\mathrm{Pb}$ (II) is presented in Fig. 3, which indicates that the adsorption increased with increasing $\mathrm{CX}, \mathrm{SiX}, \mathrm{AC}$ and Si quantity up to a certain value and then became almost constant. Therefore, the optimum CX, SiX, AC and Si quantities were selected from $0.20 \mathrm{~g} / 20 \mathrm{ml}$ of metal ions solution.

Egypt. J. Chem. 53, No.1 (2010) 


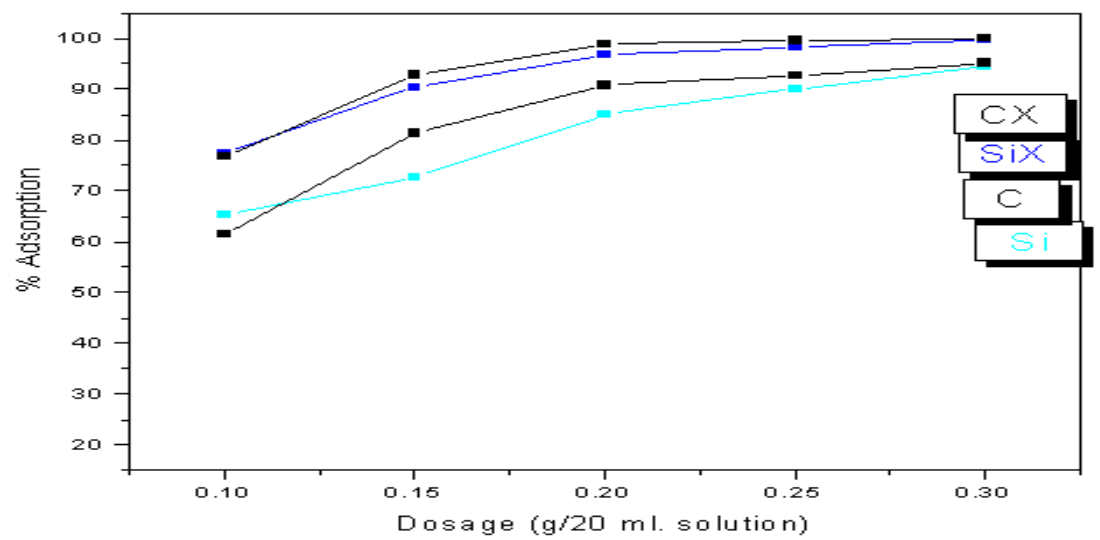

Fig. 3. Effect of $\mathrm{Si}, \mathrm{C}, \mathrm{SiX}$ and $\mathrm{CX}$ dosage on adsorption of $\mathrm{Pb}$ (II) (initial concentration $50 \mathrm{mg} / \mathrm{l}$, initial pH of solution 5.8, contact time $30 \mathrm{~min}$, temp., $298 \mathrm{~K}$ ).

\section{Effect of contact time}

The removal of lead ions increases with time and attains saturation in about $60 \mathrm{~min}$. Basically, the removal of sorbate is rapid, but it gradually decreases with time until it reaches equilibrium. Figure 4 represents the percent removal of $\mathrm{Pb}$ (II) ions versus the contact time for the initial concentration and by using the optimum $\mathrm{pH}$ value which was obtained for $\mathrm{Pb}$ (II) ions. $\mathrm{The} \mathrm{Pb}$ (II) ions showed a fast rate of sorption during the first $10 \mathrm{~min}$ of the sorbate-sorbent contact and the rate of percent removal becomes almost insignificant due to a quick exhaustion of the adsorption sites. The rate of percent metal removal is higher in the beginning due to a larger surface area of the adsorbent being available for the adsorption of the metals. The two stage sorption mechanism with the first rapid and quantitatively predominant and the second slower and quantitatively insignificant, has been extensively reported in literature ${ }^{(13)}$.

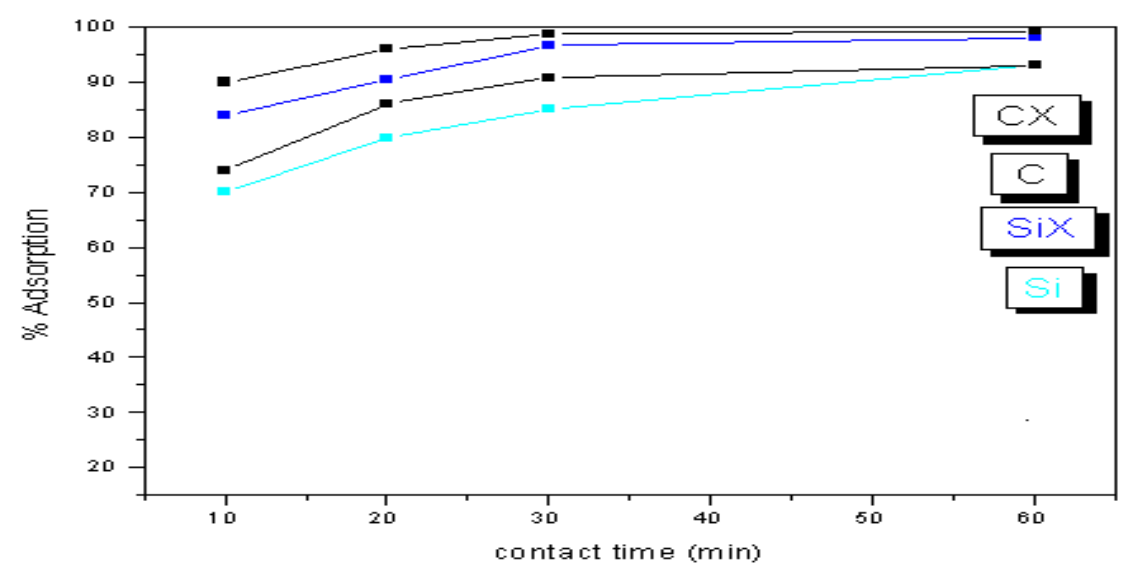

Fig. 4. Effect of contact time on adsorption of $\mathrm{Pb}$ (II) (initial concentration $30 \mathrm{mg} / \mathrm{l}, 0.2 \mathrm{~g}$, $\mathrm{Si}, \mathrm{C}$, SiX and CX / $20 \mathrm{ml}$ solution, initial pH of solution 5.8, temp., $298 \mathrm{~K}$ ). 


\section{Effect of $\mathrm{pH}$}

The effect of initial $\mathrm{pH}$ on the adsorption process is presented in Fig. 5. The $\mathrm{pH}$ is one of the most important environmental factors influencing not only site dissociation, but also the solution chemistry of the heavy metals: hydrolysis, complexation by organic and/or inorganic ligands, redox reactions, and precipitation are strongly influenced by $\mathrm{pH}$ and, on the other hand, strongly influence the adsorption availability of heavy metals ${ }^{(14)}$. As seen in Fig. 5, the adsorption percent of $\mathrm{Pb}$ (II) increased with increasing $\mathrm{pH}$ and maximum adsorption for $\mathrm{Pb}$ (II) was obtained at $\mathrm{pH} 5.8-$ which is the initial $\mathrm{pH}$ of the solutions. The $\mathrm{pH}$ of the solution, which has initial $\mathrm{pH} 5.8$ at the equilibrium conditions, was controlled and found to be 4.8. Therefore, optimum initial $\mathrm{pH}$ values of $\mathrm{Pb}$ (II) solution was chosen to be 5.8. Thus, adsorption $\mathrm{Pb}$ (II) ions on xerogel film supported on activated carbon and, silica was studied at $\mathrm{pH} 5.8$ for subsequent experiments at the equilibrium conditions.

The precipitation of $\mathrm{Pb}$ (II) ions may contribute to high uptake of the metal ions at high $\mathrm{pH}$ of solutions ${ }^{(15,16)}$. Hence, higher $\mathrm{pH}$ values were not studied.

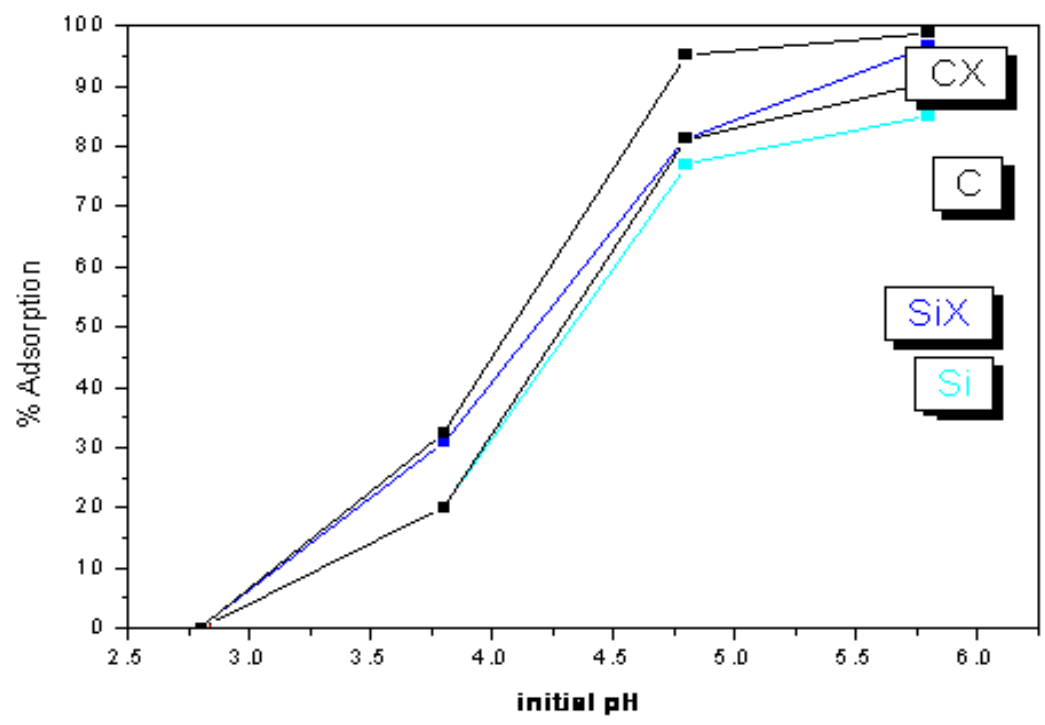

Fig. 5. Effect of initial pH on adsorption of $\mathrm{Pb}$ (II) (initial concentration $50 \mathrm{mg} / \mathrm{l}, \mathbf{0 . 2 \mathrm { g }}$ C/ 20 ml solution, contact time 30 min, temp., $298 \mathrm{~K}$ ).

\section{Conclusions}

The study indicated that carbon xerogel could be prepared from the sol gel polycondensation of resorcinol $(\mathrm{R})$ with formaldehyde $(\mathrm{F})$ followed by drying in an inert atmosphere.

Egypt. J. Chem. 53, No.1 (2010) 
Carbon xerogel film supported on activated carbon and silica exhibited more adsorption capacity of $\mathrm{Pb}$ (II) from aqueous solution than activated carbon and silica only.

Adsorption of $\mathrm{Pb}$ (II) by $\mathrm{CX}, \mathrm{SiX}$ and $\mathrm{Si}$ has been shown to depend significantly on initial concentration, the $\mathrm{pH}$, contact time, surface area and the amount of $\mathrm{CX}, \mathrm{SiX}, \mathrm{AC}$ and $\mathrm{Si}$.

The CX, SiX and Sican be considered as useful in treatment of wastewater containing $\mathrm{Pb}$ (II).

\section{References}

1. Sekar, M., Sakthi , V. and Rengaraj, S., Kinetics and equilibrium adsorption study of lead (II) onto activated carbon prepared from coconut shell. Journal of Colloid and Interface Science, 279 , 307 (2004).

2. Guidelines for Drinking-Water Quality, Vols. 1\&2, World Health Organization, Geneva (1984).

3. Marshall, I., Metal and Inorganic Waste. Water-Recycling Encyclopedia, Wayers Beta, Park Ridge, NJ (1980).

4. Okieiman, E.F., Okondia, U.E. and Ogbeifun, E.D., Sorption of cadmium and lead ions on modified groundnut. J. Chem. Technol. Biotechnol. 51, 97 (1991).

5. Rivera Utrilla, J., Ferno Garcia, M.A., Mingorance, M.D. and Bautista-Toledo, I., Adsorption of lead on activated carbons from olive stones. J. Chem. Technol. Biotechnol. 36,47 (1986).

6. Reddad, Z., Gerente, C., Andres, Y. and Le Cloirec, P., Adsorption of several metal ions onto a low-cost biosorbent: kinetic and equilibrium studies. Environ. Sci. Technol. 36 , 2067 (2002).

7. Pekala, R.W., Low density, resorcinol-formaldehyde aerogel, US Patent, 4, 873, 218 (1989).

8. Lin, C. and Ritter, J.A., Effect of synthesis pH on the structure of carbon xerogels. Carbon, 35, 1271 (1997).

9. Zanto, E.J., Al-Muhtaseb, S.A. and Ritter, J., sol-gel-derived carbon aerogels and xerogels: design of experiments approach to materials synthesis. Ind. Eng. Chem. Res. 41 , 3151 (2002).

10. Al-Muhtaseb, S.A. and Ritter, J.A., Preparation and properties of resorcinolformaldehyde organic and carbon gels Adv. Mater. 15,101 (2003).

11. Job, N., Pinard, R., Marien, J. and Pirard, J.P., Porous carbon xerogels with texture tailored by $\mathrm{pH}$ control during sol-gel process. Carbon, $\mathbf{4 2}, 619$ (2004). 
12. Pekala, R.W., Organic aerogels from the polycondensation of resorcinol with formaldehyde. J. Mater. Sci. 24,3221 (1989).

13. Saeed, A., Akhter, M.W. and Iqbal, M., Removal andrecovery of heavy metals from aqueous solution using papaya wood as a new biosorbent. Separ. Purif. Technol. 45, 25-31 (2005).

14. Esposito, A., Pagnanell, F. and Veglio, F., pH-related equilibria models for biosorption in single metal systems. Chem. Eng. Sci. 57, 307 (2002).

15. Cay, S., Uyanik, A. and Ozasik, A., Single and binary component adsorption of copper(II) and cadmium(II) from aqueous solutions using tea-industry waste. Sep. Purif. Technol. 38 , 273-280 (2004).

16. Feng, D., van Deventer, J.S.J. and Aldrich, C., Removal of pollutants from acid mine wastewater using metallurgical by-product slags. Sep. Purif. Technol. 40, 61-67 (2004).

( Received 16/11/2009; accepted 30/6/2010)
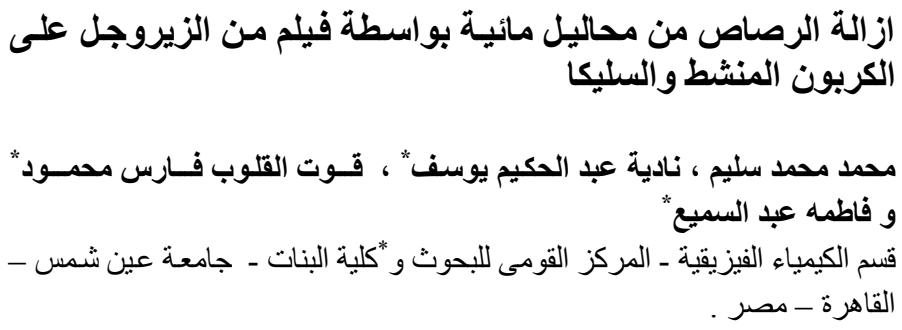

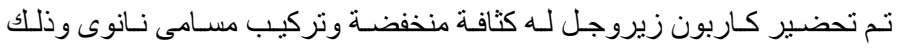

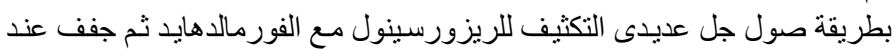

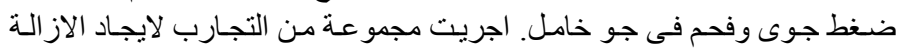

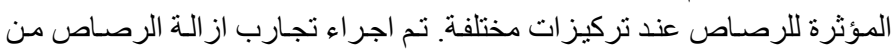

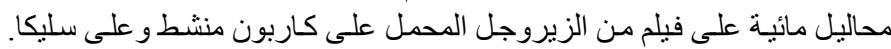

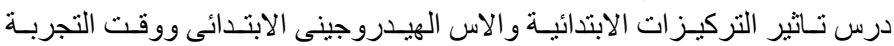

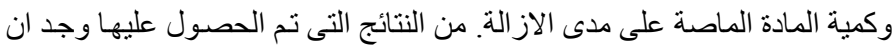

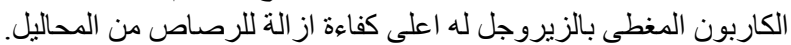

